\title{
Genome size variation in the genus Avena
}

\begin{tabular}{|c|c|}
\hline Journal: & Genome \\
\hline Manuscript ID & gen-2015-0132.R1 \\
\hline Manuscript Type: & Article \\
\hline Date Submitted by the Author: & 01-Dec-2015 \\
\hline Complete List of Authors: & $\begin{array}{l}\text { Yan, Honghai; Triticeae Research Institute of Sichuan Agricultural } \\
\text { University, } \\
\text { Martin, Sara; Agriculture and Agri-Food Canada } \\
\text { Bekele, Wubishet; Agriculture and Agri-Food Canada } \\
\text { Latta, Robert; Dalhousie University, Department of Biology } \\
\text { Diederichsen, Axel; Plant Gene Resources of Canada, Agriculture and Agri- } \\
\text { Food Canada } \\
\text { Peng, Yuanying; Triticeae Research Institute of Sichuan Agricultural } \\
\text { University } \\
\text { Tinker, Nicholas; Eastern Cereal and Oilseed Research Centre }\end{array}$ \\
\hline Keyword: & Oat, flow cytometry, nucleus, polyploidy \\
\hline
\end{tabular}




\section{Genome size variation in the genus Avena}

Honghai Yan ${ }^{\mathrm{ab}}$, Sara L. Martin ${ }^{\mathrm{a}}$, Wubishet A. Bekele ${ }^{\mathrm{a}}$, Robert G. Latta ${ }^{\mathrm{c}}$, Axel Diederichsen ${ }^{\mathrm{d}}$, Yuanying Peng ${ }^{\mathrm{b}}$, Nicholas A. Tinker ${ }^{\mathrm{a}}$

*correspondence

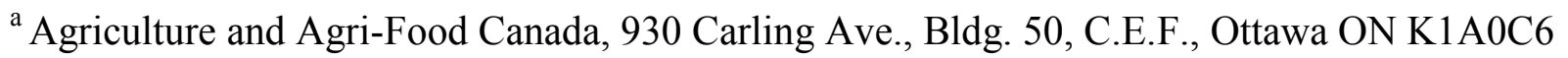
Canada

${ }^{\mathrm{b}}$ Triticeae Research Institute, Sichuan Agricultural University, Wenjiang, Chengdu 611130, Sichuan, People's Republic of China

${ }^{c}$ Department of Biology, Dalhousie University, 1355 Oxford St. Halifax NS B3H4R2 Canada

${ }^{\mathrm{d}}$ Agriculture and Agri-Food Canada, Plant Gene Resources of Canada, 107 Science Place, Saskatoon SK S7N0X2 Canada 


\begin{abstract}
Genome size is an indicator of evolutionary distance and a metric for genome characterization. Here, we report accurate estimates of genome size in 99 accessions from 26 species of Avena. We demonstrate that the average genome size of $\mathrm{C}$ genome diploid species $(2 \mathrm{C}=10.26 \mathrm{pg})$ is $15 \%$ larger than that of $\mathrm{A}$ genome species $(2 \mathrm{C}=8.95 \mathrm{pg})$ and that this difference likely accounts for a progression of size among tetraploid species, where $\mathrm{AB}<\mathrm{AC}<\mathrm{CC}$ (average $2 \mathrm{C}=16.76 \mathrm{pg}$, $18.60 \mathrm{pg}$, and $21.78 \mathrm{pg}$, respectively). All accessions from three hexaploid species with the ACD genome configuration had similar genome sizes (average $2 \mathrm{C}=25.74 \mathrm{pg}$ ). Genome size was mostly consistent within species, and in general agreement with current information about evolutionary distance among species. Results also suggest that most of the polyploid species in Avena have experienced genome downsizing in relation to their diploid progenitors. Genome size measurements could provide additional quality control for species identification in germplasm collections, especially in cases where diploid and polyploid species have similar morphology.
\end{abstract}

Keywords: Oat, flow cytometry, nucleus, polyploidy, 


\section{Introduction}

The genus Avena of the family Poaceae (Gramineae) is comprised of approximately 30 species (Baum 1977; Baum and Fedak 1985a, 1985b; Ladizinsky 1998) including three natural ploidy levels (diploid, tetraploid and hexaploid) with seven basic haploid chromosomes (Rajhathy and Morrison 1959; Rajhathy and Thomas 1974; Thomas 1992). The diploid species have either an A or $\mathrm{C}$ genome, while tetraploid species have an $\mathrm{AC}$ or $\mathrm{AB}$ genome and hexaploid species an $\mathrm{ACD}$ genome. There are no described diploid species with the B or D genome, although some oat workers have postulated A. canariensis is a candidate D genome. Based on cytogenetic evidence, both the D genome (Rajhathy and Thomas 1974) and B genome (Katsiotis et al. 1997) are highly similar to the A genome. All Avena species except for A. macrostachya, a perennial out-crossing oat, are self-pollinated annuals.

The most commonly cultivated oat is $A$. sativa L., a hexaploid species. It is an important cereal crop for both feed and human consumption with global production that ranks sixth among cereal crops (Ahmad et al. 2014). Increased oat consumption is often promoted due to nutritional attributes, including antioxidants and high soluble fiber (Rasane et al. 2015). The genus Avena is considered to be an important gene pool for oat improvement (Loskutov and Rines 2011), and many alleles conferring disease resistance have been introgressed from wild oat germplasm into cultivated oat (Thomas et al. 1975; Rooney et al. 1994). Other traits such as plant height (Frey 1991) and spikelet number (Loskutov and Rines 2011) show potentially useful genetic variation in wild oat species.

Utilization of the rich genetic diversity in wild oat relatives would be facilitated by better knowledge of genome structure and relationships among these species. Genome size is a basic 
and important metric that can provide insight into the evolutionary history of a species. Genome size is usually measured using the C-value, defined as the DNA mass in pg within an unreplicated gametic nucleus (Greilhuber et al. 2005); thus the $2 \mathrm{C}$ value represents the weight of an entire somatic nucleus, regardless of ploidy level. The Kew Plant DNA C-value database (http://data.kew.org/cvalues/) is a widely used resource that incorporates many historic and current estimates of genome size. As of the last release, the Kew database holds C-value estimates from more than 8500 plant species (Bennett and Leitch 2012).

Historically, and in the Kew database, genome size was most commonly estimated using the technique of Feulgen microdensitometry (McLeish and Sunderland 1961). However, this approach is laborious and slow (Doležel et al. 2007). Since the development of flow cytometry in the 1980 's, and due to its increased convenience, speed and accuracy, flow cytometry has become the dominant method used in genome size estimates (Doležel et al. 2007; Greilhuber et al. 2007). Based on current results in Kew Plant DNA C-values database (release 6.0, Dec. 2012) described by Bennett and Leitch (2012), 57\% of C-values have been estimated by flow cytometry while $37 \%$ have been estimated using Feulgen microdensitometry. In the most recent literature, $85 \%$ of genome size estimates were made using flow cytometry $v s .15 \%$ by microdensitometry (Bai et al. 2012).

Genome size is constant within an individual, and usually within a species (Lysák et al. 2000; Greilhuber 2005) although there are notable exceptions such as flax (Linum usitatissimum) where rapid evolution of genome size causes variation of up to $15 \%$ among accessions within the species (Cullis 2005). However, genome size can vary over several orders of magnitude in eukaryotes (Bennett and Leitch 2005; Pellicer et al. 2010a). In Angiosperms, 2C-values range from 0.13 pg in Genlisea aurea (Greilhuber et al. 2006) to 304.4 pg in Paris japonica (Pellicer et 
al. 2010b). Even among species having the same ploidy level within a single genus, genome size can differ by $>40$-fold (Bennett and Leitch 2012). Molecular investigations have shown that changes in repetitive DNAs such as retrotransposon and satellite DNA (Piegu et al. 2006) as well as low-abundance repeat-derived DNA (Kelly et al. 2015) are responsible for some of the more substantial differences in genome size observed among related species.

Genome size can have profound effects on many aspects of plant biology. For example, variations in genome size are related to phenotypic traits such as leaf size (Sugiyama 2005), leaf architecture and metabolic rates (Beaulieu et al. 2007a), seed mass (Beaulieu et al. 2007b) and cell size (Henry et al. 2014). Genome size can also be associated with adaptation to environmental conditions (Kang et al. 2014) and related phenology such as weediness and lifecycle (Leitch and Bennett 2007). Genome size has been used as an indicator for taxonomic and evolutionary studies. For example, in wild peanuts, it is believed that larger genome size is associated with species having more recent origin (Lavia and Fernández 2008). A combination of genome size, morphologic traits and SSR markers provided robust evidence in support of the taxonomy and evolution of the genus Miscanthus (Chae et al. 2014). In addition, an accurate estimate of genome size provides critical information for genome sequencing and for the calibration of genetic maps (Leitch and Bennett 2007; Ochatt 2008).

Genome size has been estimated in 16 species of Avena (Bullen and Rees 1972; Iiyama and Grant 1972; Bennett and Smith 1976; Crosby et al. 2014) excluding three that are considered to be homotypic with others in the Kew database (Baum 1977). Most estimates in the Kew database were provided by Bennett and Smith (1976) who made additional estimates and attempted to calibrate these with prior estimates. However, some apparent discrepancies and uncertainties among early estimates that were based on Feulgen microdensitometry remain in the Bennett and 
Smith (1976) publication, and therefore in the Kew database. For example, the Kew database provides very different estimates $(8.0 \mathrm{pg} v \mathrm{ps} .10 .2 \mathrm{pg})$ for two closely related species with similar A genomes: A. strigosa and A. wiestii, respectively. There is also substantial and unexpected variation in C-value estimates among the species having ACD genomes. Recent estimates based on multiple accessions of $A$. barbata suggest that its genome size is approximately $16.2 \mathrm{pg}$ (Crosby et al. 2014) which differs substantially from the reported value of $17.8 \mathrm{pg}$ in Kew. Some discrepancies may be due to variable methodologies and to lack of appropriate internal standards, but it is also notable that the works prior to and including 1976 investigated an average of only 2 accessions per species, counting an average of only 45 nuclei per replicate. Furthermore, C-value estimates for many of the 30 Avena species described by Baum (1977), Baum and Fedak (1985a, 1985b) and Ladizinsky (1998) have not been reported. A thorough reassessment of genome sizes in all species of Avena using current flow cytometric methodology would provide a critical benchmark for further genome analysis, including studies of speciation and genome evolution.

The objectives of the present study were to provide accurate estimates of genome size for 26 available species of Avena using multiple accessions per species, to evaluate intra- and interspecific genome size variation, to explore possible evolutionary models of genome size in Avena, and to evaluate flow cytometry as diagnostic tool for use in Avena germplasm characterization.

\section{Materials \& methods}

\section{Plant materials}


A total of 99 accessions of Avena including 14 diploid species, 8 tetraploid species, and 4 hexaploid species were used in this study (Table S1) with at least 3 accessions per species when adequate viable accessions were available. Seeds were provided by Plant Gene Resources of Canada (PGRC) or USDA-GRIN when not available in PGRC. The species $A$. matritensis, $A$. atherantha, A. hybrida and A. trichophylla described in Baum's (1977) monograph and A. prostrata described by Ladizinsky (1971) were not included due to lack of viable materials, and species that we considered to be homotypic are noted in Table 1.

\section{Sample preparation}

Accessions and standards were grown in cabinets. Internal standards were selected based on appropriate non-overlapping genome size and availability of self-pollinated seed from recent definitive work (Doležel et al. 1992). Seed of Vicia faba (26.90 pg/2C) originating from Doležel et al. (1992) was used as the internal standard for diploid species and tetraploid species, and seed of Pisum sativum (9.09 pg/2C) originating from Doležel et al. (1998) was used for hexaploid species. Seed from both standards was supplied by The Centre of Plant Structural and Functional Genomics (Šlechtitelů 31, 78371 Olomouc - Holice, Czech Republic). Fresh leaf tissue was harvested from young plants and kept on ice until assays were conducted, usually within three days. A leaf area of approximately $0.5 \mathrm{~cm}^{2}$ of standard and $2 \mathrm{~cm}^{2}$ of Avena species were cochopped with a razor blade for about $2-4 \mathrm{~s}$ in a petri dish containing $0.75 \mathrm{ml}$ ice-cold LB01 chopping buffer (Doležel et al. 2007). The buffer was then homogenized by several repeated pipette actions, and the solution was passed through $30 \mu \mathrm{m}$ Celltrics nylon filters (Sysmex, Lincolnshire, IL, USA) into $5 \mathrm{ml}$ round-bottom Falcon tubes (Corning, New York, NY, USA). A volume of $0.25 \mathrm{ml}(100 \mu \mathrm{g} / \mathrm{ml})$ propidium iodide (PI) staining buffer was then added and mixed by gentle shaking. Samples were incubated with the staining solution at $4{ }^{\circ} \mathrm{C}$ for 30 min prior to 
flow cytometry. Samples from both standards were co-chopped and analyzed on each day on which samples were analyzed for final adjustment to a single standard.

\section{Flow cytometry analysis}

Flow cytometry was performed using a Beckman Coulter (Miami, FL, USA) Gallios flow cytometer. The positions of peaks and the distributions of nuclei were estimated using Modfit LT version 4.0 (Verity Software House, Topsham, ME, USA). Several samples were initially tested with $>5,000$ nuclei to evaluate the coefficient of variation among nuclei $\left(\mathrm{CV}_{\mathrm{n}}\right)$ where $\mathrm{CV}_{\mathrm{n}}=\mathrm{SD} / \mathrm{M}, \mathrm{SD}$ is the standard deviation of the cell distribution, and $\mathrm{M}$ is the mean channel number (Ormerod 2008). If the $\mathrm{CV}_{\mathrm{n}}$ value of a sample or standard was more than $5 \%$, further estimates were done until chopping techniques were optimized and the $\mathrm{CV}_{\mathrm{n}}$ values were consistently less than 5\%. Most samples were then estimated with total nuclei numbers (including sample and internal standard) exceeding 1500. Some results with good quality (small $\mathrm{CV}_{\mathrm{n}} \mathrm{s}$ and good peak shape) were kept even if nuclei counts were less than 1500 but not less than 1000. All samples were analyzed with at least 3 replicates of the same individual (technical replicates) conducted over 3 different days. The formula used to calculate the absolute $2 \mathrm{C}$-value of each sample was (mean of sample G1 peak / mean of standard G1 peak) $\times 2$ C DNA content (pg) of the standard. Since two internal standards were used in this study, we used Pisum sativum as standard to calculate the $2 \mathrm{C}$-values of Vicia faba based on the average of each assessment.

\section{Statistical analysis}

The residuals from a model fitting means by accession were used to monitor homogeneity of variance, and the average coefficient of variance $\left(\mathrm{CV}_{\mathrm{t}}\right)$, calculated as the standard deviation of residuals divided by grand mean, was estimated. A nested analysis of variance (ANOVA) testing 
replicates within accessions within genomes within species within ploidy-levels was conducted using 'REML' in the SPSS software (IBM, Armonk NY, USA) Differences among species, considering accessions as replicates, were tested using one-way ANOVA followed by multiple comparison using Fisher's least significant difference (LSD) test and Tukey's honest significance difference (HSD) test within the package 'agricolae' in R.

\section{Results}

All measured values were calibrated to the published value of the Pisum sativum standard (9.09 $\mathrm{pg} / 2 \mathrm{C}$ ). After adjustment, the average $2 \mathrm{C}$-value of Vicia faba based on 29 technical replicates was $26.82 \pm 0.44 \mathrm{pg}$, which is very close to published value of $26.9 \mathrm{pg}$ (Doležel et al. 1992). The average genome sizes (2C) of 99 Avena accessions were estimated (Table S1) and data were summarized by species (Table 1). All of the flow cytometric analyses generated high-resolution histograms (e.g. Figure 1) with $\mathrm{CV}_{\mathrm{n}}$ of the $\mathrm{G} 0 / \mathrm{G} 1$ peaks ranging from $1.14 \%$ to $3.80 \%$ (mean 2.14\%). The average $\mathrm{CV}_{\mathrm{t}}$ among technical replications on separate days was $1.25 \%$, which was lower than previous reported variation (1.53\%) in diploid Triticeae species (Eilam et al. 2007). The mean 2C-values of individual accessions varied 3.1-fold, ranging from $8.41 \mathrm{pg}$ to $26.24 \mathrm{pg}$. The residuals of a model fitting the accession mean to each sample were inspected in relation to this large progression in genome size (Figure S1) and it was concluded that there was no systematic bias in variance in relation to genome size. Thus statistical methods assuming equality of variance were used in further analyses. The box plot of genome size by species (Figure 2), suggested that size variation within species is minimal and that accessions were correctly assigned to species. 
The nested ANOVA (Table 2) revealed that significant variance can be attributed to all levels of our sampling design. The differences between ploidy levels were highly significant, as expected, but there was also substantial variation among genome types with the same ploidy, as well as significant variation among species with the same genome type. Variation among accessions within a species, though appearing significant by this test, was the smallest component of the variance. Because technical replicates conducted on different days were sampled from the same plants, they cannot be considered independent samples of individuals within accessions. Variance among individuals may also be attributable to differences among plants, such as differences in the presence of dye inhibitors (Greilhuber 2005; Bennett et al. 2008). Thus, we were not able to infer true statistical differences among accessions, and this test is presented primarily as guidance to the relative scales of variance. Variance among technical replicates was substantially larger than the variation among accessions, and comparable to the variance among species within genome types.

The highly significant test showing variance among species justified further inspection of species means by LSD and HSD, both performed at $\mathrm{P}<0.05$ (Table 1). Average values by ploidy level were 9.23, 18.08, and $25.74 \mathrm{pg}$ for diploid, tetraploid, and hexaploid species, respectively, and boundaries between ploidy levels were all statistically separated. In addition, some groups of species within ploidy levels were statistically separated. Most notably, the C genome diploids had higher C-values ( $>=10.18 \mathrm{pg})$ than all A genome diploids $(<=9.23 \mathrm{pg})$, and tetraploids containing the $\mathrm{AC}$ genomes (18.51 to $18.70 \mathrm{pg}$ ) had higher $\mathrm{C}$-values than those containing the AB genomes (16.38 to $17.49 \mathrm{pg}$ ), while the single CC genome tetraploid (21.78 pg) had a markedly higher C-value than any other tetraploid species. Furthermore, there were some significant differences among A genome diploid species as well as among AB genome tetraploid 
species. For example, the diploid $A$. damascena had a lower $2 \mathrm{C}$-value $(8.43 \mathrm{pg})$ than all other species, while $A$. agadiriana had a higher $2 \mathrm{C}$ value (17.49 pg) than other AB genome species. There were no significant differences among AC genome tetraploid species, nor among ACD genome hexaploid species.

\section{Discussion}

\section{Reliability and completeness of genome size estimates in Avena}

We consider these reported $2 \mathrm{C}$-values in 26 species, including 10 previously unreported species, to be the most accurate and comprehensive genome size estimates in the genus Avena available to date. Variations among nuclei $\left(\mathrm{CV}_{\mathrm{n}}\right)$ as well as variations among technical replications $\left(\mathrm{CV}_{\mathrm{t}}\right)$ were lower than, or comparable to, values found in current literature. Although genome sizes in 16 Avena species have been reported previously (Table 3) all except for the recently published estimates in A. barbata (Crosby et al. 2014) were estimated by using Feulgen microdensitometry. While Bennett and Smith (1976) attempted to correct a bias in previous studies, most previous estimates were substantially higher than those in the current study (Table 3). This may be an inherent bias due to the use of early Feulgen microdensitometry, as suggested by Moscone et al. (2003), but it may also relate to the use in the current work of consistent internal standards as recommended by Leitch and Bennett (2007). Even with internal standards, there may still be slight systematic differences among studies caused by variable experimental factors such as the presence of dye inhibitors in plant material (Greilhuber 2005; Bennett et al. 2008) which might alter the measured peak of the standard (analogous to shifting the scale on a ruler). Thus a set of estimates such as those provided here may show high degree of relative accuracy, but could 
differ slightly from estimates in other similarly controlled experiments. Importantly, the apparent discrepancies among previous estimates (mentioned in our introduction) have now been resolved. This includes the large variation among previous estimates of closely related A genomes, and the discrepancy in prior estimates for A. barbata. It also resolves the large variation in prior estimates among the hexaploid ACD species, all of which are statistically identical in this work. While not a substantial revision from previous estimates, this work suggests that an appropriate estimate for the haploid genome of $A$. sativa is $12.85 \mathrm{pg}$, which corresponds to $12,567 \mathrm{Mbp}$ (1pg=978Mbp) (Doležel et al. 2003).

\section{Intraspecific variation in genome size}

We found very little variation of genome size among accessions within a species. This was the smallest component of total variance, and it was markedly smaller than the error variance measured among technical replicates. This finding is consistent with measurements by Bullen and Rees (1972). The existence of intraspecific variation in genome size is controversial. Although numerous studies have reported intraspecific variation (Schmuths et al. 2004; Wang et al. 2009; Díez et al. 2013), it is more common to find stability within species (Lysák et al. 2000; Greilhuber et al. 2005; Eilam e al. 2007), and some perceived intraspecific variation may be explained by other factors such as endogenous staining inhibitors or other methodical noise (Greilhuber 2005; Noirot et al. 2005; Loureiro et al. 2006). Thus, our results are consistent with the concept of intra-species stability in genome size. This is important, since the test for differences among species requires the assumption that accessions represent random samples from a population having a normal distribution. Any non-random biological differences within a species (including the misidentification of an accession) could violate this assumption, reduce 
the power of detecting a difference, and/or reduce the accuracy of estimating the species mean. Our results suggest that these factors and consequences are minimal.

A small variance among accessions was achieved partly through technical replication. Such replication may not be necessary in all cases, depending on the goals of the study, but when they are omitted, the associated error variance contributes to the perceived variation among individuals or accessions. For example, in $A$. barbata, we estimate the variance within and between accessions at 0.017 and 0.009 respectively (standard deviations of 0.13 and 0.0976 ). Since variances are additive, if technical replicates were omitted, the apparent variance among accessions would be roughly 0.026 . This is indeed comparable to the variance reported in $A$. barbata by Crosby et al (2014), who omitted technical replicates, as the initial goal of that study was to simply verify ploidy. Thus, the wide range of estimates $(15.99-16.79 \mathrm{pg})$ reported in $A$. barbata by Crosby et al (2014) need not imply intraspecific variation (Leitch and Bennett 2007; Bennett et al. 2008), and the contrast between native Old World and colonizing Californian $A$. barbata samples has yet to be verified in a strictly controlled comparison.

\section{Interspecific variation in genome size}

In contrast to intraspecific stability, numerous studies in plants have reported large variations in genome size among species within genera (Schmuths et al. 2004; Wang et al. 2009; Díez et al. 2013). Retro-elements and polyploidization are considered to be primary factors leading to the variations in genome size (Piegu et al. 2006; Grover and Wendel 2010). In this study, variation among ploidy levels was substantial, and was obviously driven by genome duplication, while variation within ploidy levels was generally consistent with prior sub-genome designations. The $2 \mathrm{C}$-values of species with identical genomic constitutions were generally continuous with only 
minor differences. This suggests that there have been no major events driving divergence within a genome type, and this is consistent with observations in the related Triticeae genera (Eilam et al. 2007). Small but significant variations were detected, even among closely-related diploids with identical sub-genome designations by the LSD test. For instance, within the $\mathrm{A}_{\mathrm{s}}$ genome diploid species, the genome of $A$. lusitanica was significantly smaller $(\mathrm{P}<=0.05)$ than all others except for A. hispanica, and was close in size to the smallest $\mathrm{A}_{\mathrm{d}}$ genome diploid A. damascena. Molecular evidence (Fu and William 2008; Peng et al. 2010; Yan et al. 2014) also showed that $A$. lusitanica was more closely related to A. damascena than to other $\mathrm{A}_{\mathrm{s}}$ genome diploids. However, the differences between A. lusitanica and other $\mathrm{A}_{\mathrm{s}}$ genome diploids were not judged significant by HSD, hence this result should be investigated further.

Most notably, our results showed that the $\mathrm{C}$ genome has a larger genome size than other subgenomes. Based on averages within the $\mathrm{A}$ and $\mathrm{C}$ genome diploids, the difference in size is approximately $15 \%$. This difference was also observed by Iiyama and Grant (1972), although the large variation among A genomes reported by these authors made this difference less striking, and the average difference that they reported was closer to $10 \%$. The apparent divergence between the A and $\mathrm{C}$ sub-genomes is supported by previous studies showing major cytogenetic differences between $\mathrm{A}$ and $\mathrm{C}$ genome chromosomes that are most likely due to differences in repetitive DNA content (Fominaya et al. 1988; Linares et al. 1992; Jellen et al. 1993). Within hexaploid species, the $\mathrm{C}$ genome contains a greater number of large heterochromatic regions than the A or D genomes (Fominaya et al. 1988; Linares et al. 1992; Jellen et al. 1993). In future work, it will be interesting to compare these variations in genome size with other genomic indicators of speciation. 


\section{Genome size as a diagnostic tool}

Since species identification in Avena is difficult, it is possible to find misidentified accessions within large genebank collections. Such misidentifications can result in wasted resources and erroneous scientific results. Some misidentifications can be corrected through morphological observation, but this requires extensive field- or greenhouse-scale grow-outs, trained experts, and substantial investment in time. In contrast, flow-cytometric assays on seedlings are rapid and inexpensive, and these could be used to screen large collections in support of correct identification. This possibility was suggested through the work of Crosby et al. (2014) in which unexpected variation in ploidy level was observed among accessions previously identified as $A$. barbata. Here, and elsewhere in the genus Avena (e.g. A. sterilis vs $A$. insularis), it appears that species having similar morphology but different ploidy levels is common. In such cases a single replication of flow cytometry would effectively identify errors. However, multiple replications together with a series of standard check varieties would be required to detect the smaller differences identified in this work. Flow cytometry could also be used in parallel with highthroughput marker analysis, and could alleviate anticipated problems in the use of markers to distinguish among species that carry closely-related sub-genomes in different combinations and ploidy levels.

\section{Genome size reduction after polyploidization}

The availability of tetraploid and hexaploid species together with their diploid progenitor genomes provided an opportunity to test for additivity in the size of sub-genome components. Since diploid representatives of the B- and D-genomes are not known, but the genomes are considered to be similar to the A genome (Rajhathy and Thomas 1974; Leggett and Markhand 
1995; Katsiotis et al. 1997; Shelukhina et al. 2008; Peng et al. 2010), the average A and C genome sizes of the diploids were used to model predicted polyploid genome sizes (Figure 3). These predictions suggest that polyploid species have genome sizes similar to the sum of their putative genome progenitors, but that a systematic downsizing has occurred in all of the polyploid species except for the perennial tetraploid species A. macrostachya. An alternate (or additional) explanation could be that the unknown B and D genomes are actually smaller than the observed A genomes. The hypothesis that the B genome is smaller than the A genome was put forward by Iiyama and Grant (1972) for this reason, although this was also in support of a proposed AABBDD genome constitution for the hexaploid, which has been subsequently rejected. Polyploid genome downsizing has been observed in most angiosperms, and is assumed to be a general trend (Kellogg and Bennetzen 2004; Pellicer et al. 2010a). The mechanisms leading to loss of the DNA in polyploids include unequal homologous recombination (Bennetzen et al. 2005), non-homologous recombination (Devos et al. 2002), general elimination of redundant DNA (Ozkan et al. 2003; Leitch and Bennett 2004) and specific elimination of duplicate genes (Renny-Byfield and Wendel 2014; Evans et al. 2015). It is interesting that $A$. macrostachya, the only known perennial outcrossing species in Avena, appears to show the opposite trend (genome inflation). However, an alternate explanation for this deviation in $A$. macrostachya could be that the $\mathrm{C}_{\mathrm{m}}$ genome differs substantially in size from the diploid $\mathrm{C}$ genomes observed in this study. It has been suggested that $C_{m}$ is ancestral to the $C$ genome type (Rodionov et al. 2005; Badaeva et al. 2010), and large differences in chromosome morphology and heterochromatin distribution have been observed in A. macrostachya relative to other C genome diploids (Hutchinson and Postoyko 1986; Rodionov et al. 2005; Badaeva et al. 2010). Furthermore, symmetrical chromosomes as well as large heterochromatic blocks are more 
apparent in A. macrostachya than in other Avena species. Thus, Badaeva et al. (2010) suggested that A. macrostachya formed via chromosome duplication from an ancestral C genome diploid that is no longer extant, and that this occurred prior to the formation of the present $\mathrm{C}$ and $\mathrm{A}$ genomes. Our results support this hypothesis, although other explanations cannot be excluded at this stage.

\section{Conclusion}

The genome sizes reported here for most of the recognized species in the genus Avena should provide consistent and reliable benchmarks to assist in further characterization of the evolutionary relationships among these important species. Furthermore, these estimates will facilitate the planning and calibration of future mapping and genome sequencing efforts. It is fortunate that substantial diversity in the genus Avena has been preserved in many national germplasm collections, but the number of accessions from some species is quite limited. Further characterization of diversity in the genus Avena is needed in order to inform future decisions on germplasm collection, conservation, and utilization.

\section{Acknowledgements}

We thank Paul Kron for expert advice regarding flow cytometry, and members of the Canadian and US Genebank teams for expert assistance in maintaining and providing germplasm. This work was made possible by outstanding technical assistance from Charlene Wight and Kathie 
Upton. This work was funded by an AAFC Crop Genomics project. Funding for H. Yan was provided by a China Ministry of Education scholarship.

\section{References:}

Ahmad, M., Gul-Zaffar, Z.A., and Habib, M. 2014. A review on Oat (Avena sativa L.) as a dualpurpose crop. Sci. Res. Essays. 9(4): 52-59. doi:10.5897/SRE2014.5820.

Badaeva, E.D., Shelukhina, O.Y., Diederichsen, A., Loskutov, I.G., and Pukhalskiy, V.A. 2010. Comparative cytogenetic analysis of Avena macrostachya and diploid C-genome Avena species. Genome, 53(2), 125-137. doi:10.1139/G09-089.

Bai, C., Alverson, W.S., Follansbee, A., and Waller, D.M. 2012. New reports of nuclear DNA content for 407 vascular plant taxa from the United States. Ann. Bot. 110(8): 1623-1629. doi: 10.1093/aob/mcs222.

Baum, B.R. 1977. Oats: Wild and cultivated. A monograph of the genus Avena L. (Poaceae). Minister of Supply and Services Canada, Ottawa, Ontario: Agriculture Canada.

Baum, B.R., and Fedak, G. 1985a. Avena atlantica, a new diploid species of the oat genus from Morocco. Can. J. Bot. 63(6): 1057-1060. doi:10.1139/b85-144.

Baum, B.R., and Fedak, G. 1985b. A new tetraploid species of Avena discovered in Morocco. Can. J. Bot. 63(8): 1379-1385. doi:10.1139/b85-191.

Beaulieu, J.M., Leitch, I.J., and Knight, C.A. 2007a. Genome size evolution in relation to leaf strategy and metabolic rates revisited. Ann. Bot. 99(3): 495-505. doi:10.1093/aob/mcl271. 
Beaulieu, J.M., Moles, A.T., Leitch, I.J., Bennett, M.D., Dickie, J.B., and Knight, C.A. $2007 b$. Correlated evolution of genome size and seed mass. New Phytol. 173(2), 422-437. doi:10.1111/j.1469-8137.2006.01919.x.

Bennett, M.D., and Smith, J.B. 1976. Nuclear DNA amounts in angiosperms. Philos T Roy Soc B. 274(933): 227-274. doi:10.1098/rstb.1976.0044.

Bennett, M.D., and Leitch, I.J. 2005. Nuclear DNA amounts in angiosperms: progress, problems and prospects. Ann. Bot. 95(1): 45-90. doi:10.1093/aob/mci003.

Bennett, M.D., H, J.P., and J, S.J. 2008. Anthocyanin inhibits propidium iodide DNA fluorescence in Euphorbia pulcherrima: implications for genome size variation and flow cytometry. Ann. Bot. 101(6): 777-790. doi:10.1093/aob/mcm303.

Bennett, M.D., and Leitch, I.J. 2012. Plant DNA C-values database (release 6.0, Dec. 2012). Accessible http://www.kew.org/cvalues/.

Bennetzen, J.L., Ma, J., and Devos, K.M. 2005. Mechanisms of recent genome size variation in flowering plants. Ann. Bot. 95(1): 127-132. doi:10.1093/aob/mci008.

Bullen, M.R., and Rees, H. 1972. Nuclear variation within Avenae. Chromosoma, 39(1): 93-100. doi:10.1007/BF00320593.

Chae, W.B., Hong, S.J., Gifford, J.M., Rayburn, A.L., Sacks, E.J., and Juvik, J.A. 2014. Plant morphology, genome size, and SSR markers differentiate five distinct taxonomic groups among accessions in the genus Miscanthus. Glob Change Biol Bioenergy. 6(6): 646-660. doi:10.1111/gcbb.12101. 
Crosby, K., Stokes, T.O., and Latta, R.G. 2014. Evolving California genotypes of Avena barbata are derived from multiple introductions but still maintain substantial population structure. Peer J. 2: e633. doi:10.7717/peerj.633.

Cullis, C.A. 2005. Mechanisms and control of rapid genomic changes in flax. Ann. Bot. 95(1): 201-206. doi:10.1093/aob/mci013.

Devos, K.M., Brown, J.K.M., and Bennetzen, J.L. 2002. Genome size reduction through illegitimate recombination counteracts genome expansion in Arabidopsis. Genome Res. 12(7): 1075-1079. doi:10.1101/gr.132102.

Díez, C.M., Gaut, B.S., Meca, E., Scheinvar, E., Montes-Hernandez, S., Eguiarte, L.E., and Tenaillon, M.I. 2013. Genome size variation in wild and cultivated maize along altitudinal gradients. New Phytol. 199(1): 264-276. doi:10.1111/nph.12247.

Doležel, J., Sgorbati, S., and Lucretti, S. 1992. Comparison of three DNA fluorochromes for flow cytometric estimation of nuclear DNA content in plants. Physiol Plantarum. 85(4): 625-631. doi:10.1111/j.1399-3054.1992.tb04764.x.

Doležel, J., Greilhuber, J., Lucretti, S., Meister, A., Lysák, M.A., Nardi, L., and Obermayer, R. 1998. Plant genome size estimation by flow cytometry: inter-laboratory comparison. Ann. Bot. 82(suppl 1): 17-26.

Doležel, J., Bartoš, J., Voglmayr, H., and Greilhuber, J. 2003. Nuclear DNA content and genome size of trout and human. Cytom Part A. 51: 127-8. doi:10.1002/cyto.a.10013.

Doležel, J., Greilhuber, J., and Suda, J. 2007. Estimation of nuclear DNA content in plants using flow cytometry. Nat. Protoc. 2(9): 2233-2244. doi:10.1038/nprot.2007.310. 
Eilam, T., Anikster, Y., Millet, E., Manisterski, J., Sagi-Assif, O., and Feldman, M. 2007.

Genome size and genome evolution in diploid Triticeae species. Genome, 50(11): 1029-1037. doi:10.1139/G07-083.

Evans, J., Crisovan, E., Barry, K., Daum, C., Jenkins, J., Kunde-Ramamoorthy, G., Nandety, A., Ngan, C.Y., Vaillancourt, B., and Wei, C.L. 2015. Diversity and Population Structure of Northern Switchgrass as Revealed Through Exome Capture Sequencing. Plant J. 84(4): 800-815. doi:10.1111/tpj.13041.

Fominaya, A., Vega, C., and Ferrer, E. 1988. Giemsa C-banded karyotypes of Avena species. Genome, 30(5): 627-632. doi:10.1139/g88-106.

Frey, K.J.1991. Genetic resources of oats. In: Use of plant introductions in cultivar development. Part1. CSSA Special Publication. Edited by H.L Shands and L.E Weisner. Madison, Wisconsin. pp.15-24.

Fu, Y.B., and Williams, D.J. 2008. AFLP variation in 25 Avena species. Theor. Appl. Genet. 117(3): 333-342. doi:10.1007/s00122-008-0778-3.

Greilhuber, J. 2005. Intraspecific variation in genome size in angiosperms: identifying its existence. Ann. Bot. 95(1): 91-98. doi:10.1093/aob/mci004.

Greilhuber, J., Doležel, J., Lysák, M.A., and Bennett, M.D. 2005. The origin, evolution and proposed stabilization of the terms 'genome size'and ' $\mathrm{C}$-value'to describe nuclear DNA contents. Ann. Bot. 95(1): 255-260. doi:10.1093/aob/mci019. 
Greilhuber, J., Borsch, T., Müller, K., Worberg, A., Porembski, S., and Barthlott, W. 2006.

Smallest angiosperm genomes found in Lentibulariaceae, with chromosomes of bacterial size. Plant Biol. 8(6): 770-777. doi:10.1055/s-2006-924101.

Greilhuber, J., Temsch, E.M., and Loureiro, J. 2007. Nuclear DNA content measurement. In: Flow cytometry with plant cells: analysis of genes, chromosomes and genomes. Edited by J. Doležel, J. Greilhuber and J. Suda. Wiley-VCH Verlag GmbH \& Co. KGaA, Weinheim, Germany. pp. 67-101.

Grover, C.E., and Wendel, J.F. 2010. Recent insights into mechanisms of genome size change in plants. J. Bot. 2010. doi:10.1155/2010/382732.

Henry, T.A., Bainard, J.D., and Newmaster, S.G. 2014. Genome size evolution in Ontario ferns (Polypodiidae): evolutionary correlations with cell size, spore size, and habitat type and an absence of genome downsizing. Genome, 57(10): 555-566. doi:10.1139/gen-2014-0090.

Hutchinson, J., Postoyko, J., Horn, W., Jensen, C. J., Odenbach, W., and Schieder, O. 1986. “Cbanding of Avena species." Genetic manipulation in plant breeding. In: Proceedings international symposium organized by Eucarpia, September 8-13, 1985, Berlin (West), Germany. pp. 157-159.

Iiyama, K., and Grant, W.F. 1972. A correlation of nuclear DNA content and thin-layer chromatographic patterns in resolving genome relationships in Avena. Can. J. Bot. 50(7), 15291545. doi:10.1139/b72-190.

Jellen, E.N., Phillips, R.L., and Rines, H.W. 1993. C-banded karyotypes and polymorphisms in hexaploid oat accessions (Avena spp.) using Wright's stain. Genome, 36(6): 1129-1137. doi:10.1139/g93-151. 
Kang, M., Tao, J., Wang, J., Ren, C., Qi, Q., Xiang, Q.Y., and Huang, H. 2014. Adaptive and nonadaptive genome size evolution in Karst endemic flora of China. New Phytol. 202(4): 13711381. doi:10.1111/nph.12726.

Katsiotis, A., Loukas, M., and Heslop-Harrison, J.S. 1997. The close relationship between the A and B genomes in Avena L. (Poaceae) determined by molecular cytogenetic analysis of total genomic, tandemly and dispersed repetitive DNA sequences. Ann. Bot. 79: 103-109. doi:10.1006/anbo.1996.0312.

Kellogg, E.A., and Bennetzen, J.L. 2004. The evolution of nuclear genome structure in seed plants. Am. J. Bot. 91(10): 1709-1725. doi:10.3732/ajb.91.10.1709.

Kelly, L.J., Renny-Byfield, S., Pellicer, J., Macas, J., Novák, P., Neumann, P., Lysak, M.A., Day, P.D., Berger, M., Fay, M.F., Nichols, R.A., Leitch, A.R., and Leitch, I.J. 2015. Analysis of the giant genomes of Fritillaria (Liliaceae) indicates that a lack of DNA removal characterizes extreme expansions in genome size. New Phytol. 208(2): 596-607. doi:10.1111/nph.13471.

Ladizinsky, G. 1998. A new species of Avena from Sicily, possibly the tetraploid progenitor of hexaploid oats. Genet Resour Crop Evol. 45(3): 263-269. doi:10.1023/A:1008657530466.

Ladizinsky, G. 1971. Avena prostrata: a new diploid species of oat. Israel J Bot. 20: 297-301.

Lavia, G.I., and Fernández, A. 2008. Genome size in wild and cultivated peanut germplasm. Plant Syst Evol. 272(1-4): 1-10. doi:10.1007/s00606-007-0632-0.

Leggett, J.M., and Markhand, G.S. 1995. The genomic structure of Avena revealed by GISH. In: Kew chromosome conference IV. Edited by P.E. Brandham and M.D. Bennett. Royal Botanic Gardens, Kew. pp. 133-139. 
Leitch, I.J., and Bennett, M.D. 2004. Genome downsizing in polyploid plants. Biol. J. Linn. Soc. 82(4): 651-663. doi:10.1111/j.1095-8312.2004.00349.x.

Leitch, I.J., and Bennett, M.D. 2007. Genome size and its uses: the impact of flow cytometry. In: Flow cytometry with plant cells: analysis of genes, chromosomes and genomes. Edited by J.

Doležel, J. Greilhuber and J. Suda. Wiley-VCH Verlag GmbH \& Co. KGaA, Weinheim, Germany. pp. 153-176.Linares, C., Vega, C., Ferrer, E., and Fominaya, A. 1992. Identification of C-banded chromosomes in meiosis and the analysis of nucleolar activity in Avena byzantina $\mathrm{C}$. Koch cv 'Kanota'. Theor. Appl. Genet. 83(5): 650-654. doi:10.1007/BF00226911.

Loskutov, I.G. 2008. On evolutionary pathways of Avena species. Genet Res Crop Evol 55(2): 211-220. doi:10.1007/s10722-007-9229-2

Loskutov, I.G., and Rines, H.W. 2011. Avena. In Wild Crop Relatives: Genomic and Breeding Resources. Edited by C. Kole. Springer press, Heidelberg. pp.109-183.

Loureiro, J., Rodriguez, E., DOLEŽEL, J., and Santos, C. 2006. Flow cytometric and microscopic analysis of the effect of tannic acid on plant nuclei and estimation of DNA content. Ann. Bot. 98(3): 515-527. doi:10.1093/aob/mcl140.

Lysák, M.A., Rostková, A., Dixon, J.M., Rossi, G., and Doležel, J. 2000. Limited genome size variation in Sesleria albicans. Ann. Bot. 86(2): 399-403. doi:10.1006/anbo.2000.1200.

McLeish, J., and Sunderland, N. 1961. Measurements of deoxyribosenucleic acid (DNA) in higher plants by Feulgen photometry and chemical methods. Exp Cell Res. 24(3): 527-540. doi:10.1016/0014-4827(61)90452-9. 
Moscone, E.A., Baranyi, M., Ebert, I., Greilhuber, J., Ehrendorfer, F., and Hunziker, A.T. 2003. Analysis of nuclear DNA content in Capsicum (Solanaceae) by flow cytometry and Feulgen densitometry. Ann. Bot. 92(1): 21-29. doi:10.1093/aob/mcg105.

Noirot, M., Barre, P., Duperray, C., Hamon, S., and De Kochko, A. 2005. Investigation on the causes of stoichiometric error in genome size estimation using heat experiments: consequences on data interpretation. Ann. Bot. 95(1): 111-118. doi:10.1093/aob/mci006.

Ochatt, S.J. 2008. Flow cytometry in plant breeding. Cytom Part A. 73(7): 581-598. doi:10.1002/cyto.a.20562.

Ormerod, M.G., and Novo, D. 2008. Data analysis. In: Flow cytometry: a basic introduction. Edited by M.G. Ormeroded. Los Angeles: De Novo Software.

Ozkan, H., Tuna, M., and Arumuganathan, K. 2003. Nonadditive changes in genome size during allopolyploidization in the wheat (Aegilops-Triticum) group. J. Hered. 94(3): 260-264. doi:10.1093/jhered/esg053.

Pellicer, J., Garcia, S., Canela, M.A., Garnatje, T., Korobkov, A.A., Twibell, J.D., and Vallès, J. 2010a. Genome size dynamics in Artemisia L.(Asteraceae): following the track of polyploidy. Plant Biol. 12(5): 820-830. doi:10.1111/j.1438-8677.2009.00268.x.

Pellicer, J., Fay, M. F., and Leitch, I.J. 2010b. The largest eukaryotic genome of them all?. Bot. J. Linn. Soc. 164(1): 10-15. doi:10.1111/j.1095-8339.2010.01072.x.

Peng, Y.Y., Wei, Y M., Baum, B.R., Yan, Z.H., Lan, X.J., Dai, S.F., and Zheng, Y.L. 2010. Phylogenetic inferences in Avena based on analysis of FL intron2 sequences. Theor. Appl. Genet. 121(5): 985-1000. doi:10.1007/s00122-010-1367-9. 
Piegu, B., Guyot, R., Picault, N., Roulin, A., Saniyal, A., Kim, H., Collura, K., Brar, D.S., Jackson, S., Wing, R.A., and Panaud, O. 2006. Doubling genome size without polyploidization: dynamics of retrotransposition-driven genomic expansions in Oryza australiensis, a wild relative of rice. Genome Res. 16(10): 1262-1269. doi:10.1101/gr.5290206.

Rajhathy, T., and Morrison, J.W. 1959. Chromosome morphology in the genus Avena. Can. J. Bot. 37: 331-337. doi:10.1139/b59-024.

Rajhathy, T., and Thomas, H. 1974. Cytogenetics of oats (Avena L.) Ottawa: Genetics Society of Canada 90p. Miscellaneous Publications of the Genetics Society of Canada, (2).

Rasane, P., Jha, A., Sabikhi, L., Kumar, A., and Unnikrishnan, V. S. 2015. Nutritional advantages of oats and opportunities for its processing as value added foods-a review. J. Food. Sci. Technol. 52(2): 662-675. doi:10.1007/s13197-013-1072-1.

Renny-Byfield, S., and Wendel, J.F. 2014. Doubling down on genomes: polyploidy and crop plants. Am. J. Bot. 101(10): 1711-1725. doi:10.3732/ajb.1400119.

Rodionov, A.V., Tyupa, N.B., Kim, E.S., Machs, E.M., and Loskutov, I.G. 2005. Genomic configuration of the autotetraploid oat species Avena macrostachya inferred from comparative analysis of ITS1 and ITS2 sequences: on the oat karyotype evolution during the early events of the Avena species divergence. Russ. J. Genet. 41(5): 518-528. doi:10.1007/s11177-005-0120-y. Rooney, W.L., Rines, H.W., and Phillips, R.L. 1994. Identification of RFLP Markers Linked to Crown Rust Resistance Genes Pc 91 and Pc in Oat. Crop Sci. 34(4): 940-944. doi:10.2135/cropsci1994.0011183X003400040019x. 
Schmuths, H., Meister, A., Horres, R., and Bachmann, K. 2004. Genome size variation among accessions of Arabidopsis thaliana. Ann. Bot. 93(3): 317-321. doi:10.1093/aob/mch037.

Shelukhina, O.Y., Badaeva, E.D., Brezhneva, T.A., Loskutov, I.G., and Pukhalsky, V.A. 2008. Comparative analysis of diploid species of Avena L. using cytogenetic and biochemical markers: Avena canariensis Baum et Fedak and A. longiglumis Dur. Russ. J. Genet. 44(6): 694-701. doi:10.1134/S1022795408060094.

Sugiyama, S. 2005. Developmental basis of interspecific differences in leaf size and specific leaf area among C3 grass species. Func. Ecol. 19(6): 916-924. doi:10.1111/j.13652435.2005.01044.x.

Thomas, H., Leggett, J.M., and Jones, I.T. 1975. The addition of a pair of chromosomes of the wild oat Avena barbata $(2 \mathrm{n}=28)$ to the cultivated oat $A$. sativa L. $(2 \mathrm{n}=42)$. Euphytica, 24(3): 717-724. doi:10.1007/BF00132910.

Thomas, H. 1992. Cytogenetics of Avena. In: Oat Science and Technology, Monograph 33, Agronomy Series. Edited by H.G. Marshall and M.E. Sorrells. Madison, Wisconsin. pp. 473-508.

Wang, Y., Bigelow, C.A., and Jiang, Y. 2009. Ploidy level and DNA content of perennial ryegrass germplasm as determined by flow cytometry. HortScience, 44(7): 2049-2052.

Yan, H.H., Baum, B.R., Zhou, P.P., Zhao, J., Wei, Y.M., Ren, C.Z., Xiong, F.Q., Liu, G., Zhong, Lin., Zhao, G., and Peng, Y.Y. 2014. Phylogenetic analysis of the genus Avena based on chloroplast intergenic spacer $p s b$ A-trn $H$ and single-copy nuclear gene Acc1. Genome, 57(5): 267-277. doi:10.1139/gen-2014-0075. 
Table 1. List of Avena species in order of increasing genome size (as measured) including ploidy levels, predicted haplomes, number of accessions measured, mean $2 \mathrm{C}$ - values with standard deviations and ranges, LSD test, HSD test, and internal standards used in measurement.

\begin{tabular}{|c|c|c|c|c|c|c|c|c|}
\hline Species $^{a}$ & Haplome & $\begin{array}{l}\text { Ploidy } \\
\text { level }\end{array}$ & $\begin{array}{l}\text { No. of } \\
\text { accessions }\end{array}$ & $\begin{array}{l}\text { Mean 2C values } \\
\pm \mathrm{S} . \mathrm{D}(\text { pg DNA })^{b}\end{array}$ & $\begin{array}{l}\text { 2C-value range } \\
\text { (pg DNA) }\end{array}$ & $\begin{array}{l}\text { LSD } \\
\text { test }^{c}\end{array}$ & $\begin{array}{l}\text { HSD } \\
\text { test }^{d}\end{array}$ & $\begin{array}{l}\text { Internal } \\
\text { standard }^{e}\end{array}$ \\
\hline A. damascena & $\mathrm{A}_{\mathrm{d}}$ & $2 n=2 x$ & 3 & $8.43 \pm 0.11$ & $8.41-8.45$ & $\mathrm{a}$ & $\mathrm{a}$ & $\mathrm{V}$ \\
\hline A. lusitanica & $\mathrm{A}_{\mathrm{s}}$ & $2 n=2 x$ & 3 & $8.72 \pm 0.28$ & $8.52-8.92$ & $\mathrm{~b}$ & $a b$ & V \\
\hline A. canariensis & $\mathrm{A}_{\mathrm{c}}$ & $2 n=2 x$ & 5 & $8.80 \pm 0.13$ & $8.70-8.93$ & $\mathrm{~b}$ & $a b$ & V \\
\hline A. hispanica & $\mathrm{A}_{\mathrm{s}}$ & $2 n=2 x$ & 3 & $8.80 \pm 0.14$ & $8.71-8.96$ & $\mathrm{~b}$ & $\mathrm{~b}$ & V \\
\hline A. brevis & $\mathrm{A}_{\mathrm{s}}$ & $2 n=2 x$ & 3 & $8.98 \pm 0.25$ & $8.77-9.09$ & $\mathrm{c}$ & $\mathrm{bc}$ & $\mathrm{V}$ \\
\hline A. hirtula & $\mathrm{A}_{\mathrm{s}}$ & $2 n=2 x$ & 3 & $9.08 \pm 0.11$ & $9.01-9.13$ & $\mathrm{c}$ & $\mathrm{bc}$ & V \\
\hline A. nuda & $\mathrm{A}_{\mathrm{s}}$ & $2 n=2 x$ & 3 & $9.08 \pm 0.17$ & $9.00-9.19$ & $\mathrm{~cd}$ & $\mathrm{bc}$ & V \\
\hline A. strigosa & $\mathrm{A}_{\mathrm{s}}$ & $2 n=2 x$ & 10 & $9.07 \pm 0.22$ & $8.74-9.38$ & $\mathrm{~cd}$ & $\mathrm{bc}$ & V \\
\hline A. wiestii & $\mathrm{A}_{\mathrm{s}}$ & $2 n=2 x$ & 2 & $9.08 \pm 0.20$ & $9.04-9.10$ & $\mathrm{~cd}$ & $\mathrm{bc}$ & V \\
\hline A. atlantica & $\mathrm{A}_{\mathrm{s}}$ & $2 n=2 x$ & 4 & $9.22 \pm 0.24$ & $8.94-9.52$ & d & $\mathrm{c}$ & V \\
\hline A. longiglumis & $A_{l}$ & $2 n=2 x$ & 3 & $9.23 \pm 0.20$ & $9.11-9.42$ & $\mathrm{~d}$ & $\mathrm{c}$ & V \\
\hline A. clauda & $\mathrm{C}_{\mathrm{p}}$ & $2 n=2 x$ & 3 & $10.31 \pm 0.12$ & $10.26-10.41$ & $\mathrm{e}$ & $d$ & V \\
\hline A. eriantha & $\mathrm{C}_{\mathrm{p}}$ & $2 n=2 x$ & 3 & $10.18 \pm 0.22$ & $10.02-10.33$ & e & d & V \\
\hline A. ventricosa & $\mathrm{C}_{\mathrm{v}}$ & $2 n=2 x$ & 2 & $10.29 \pm 0.25$ & $10.19-10.36$ & $\mathrm{e}$ & $\mathrm{d}$ & V \\
\hline A. barbata & $\mathrm{AB}$ & $2 n=4 x$ & 5 & $16.42 \pm 0.15$ & $16.32-16.58$ & $\mathrm{f}$ & $\mathrm{e}$ & $\mathrm{V}$ \\
\hline A. vaviloviana & $\mathrm{AB}$ & $2 n=4 x$ & 5 & $16.38 \pm 0.18$ & $16.31-16.62$ & $\mathrm{f}$ & $\mathrm{d}$ & V \\
\hline A. abyssinica & $\mathrm{AB}$ & $2 n=4 x$ & 4 & $16.73 \pm 0.29$ & $16.49-16.97$ & $\mathrm{~g}$ & $\mathrm{f}$ & V \\
\hline A. agadiriana & $\mathrm{AB}$ & $2 n=4 x$ & 4 & $17.49 \pm 0.24$ & $17.23-17.68$ & $\mathrm{~h}$ & g & $\mathrm{V}$ \\
\hline A. insularis & $A C^{f}$ & $2 n=4 x$ & 3 & $18.59 \pm 0.17$ & $18.43-18.79$ & $\mathrm{i}$ & $\mathrm{h}$ & V \\
\hline A. maroccana & $\mathrm{AC}$ & $2 n=4 x$ & 3 & $18.51 \pm 0.20$ & $18.31-18.67$ & $\mathrm{i}$ & $\mathrm{h}$ & $\mathrm{V}$ \\
\hline A. murphyi & $\mathrm{AC}$ & $2 n=4 x$ & 1 & $18.70 \pm 0.32$ & $18.56-19.13$ & $\mathrm{i}$ & $\mathrm{h}$ & V \\
\hline A. macrostachya & $\mathrm{C}_{\mathrm{m}} \mathrm{C}_{\mathrm{m}}$ & $2 n=4 x$ & 1 & $21.78 \pm 0.20$ & NA & NA & NA & V \\
\hline A. fatua & $\mathrm{ACD}$ & $2 n=6 x$ & 3 & $25.81 \pm 0.18$ & $25.76-25.90$ & $\mathrm{k}$ & $\mathrm{i}$ & $P$ \\
\hline A. occidentalis & $\mathrm{ACD}$ & $2 n=6 x$ & 3 & $25.69 \pm 0.27$ & $25.44-25.81$ & $\mathrm{k}$ & $\mathrm{i}$ & $\mathrm{P}$ \\
\hline A. sativa & $\mathrm{ACD}$ & $2 n=6 x$ & 13 & $25.70 \pm 0.40$ & $25.30-26.24$ & $\mathrm{k}$ & I & $P$ \\
\hline A. sterilis & $\mathrm{ACD}$ & $2 n=6 x$ & 4 & $25.75 \pm 0.23$ & $25.49-25.94$ & $\mathrm{k}$ & $\mathrm{i}$ & $\mathrm{P}$ \\
\hline
\end{tabular}

${ }^{a}$ Species that are considered in this work to be homotypic include: $A$. nudi-brevis $(=A$. nuda $), A$. pilosa $(=A$. eriantha $)$, A. magna (=A. maroccana), . ludoviciana $(=A$. sterilis $)$, A. byzantina $(=A$. sativa). The incorrect use of " $A$. nuda" to refer to a hulless hexaploid species has been corrected to the accepted classification within $A$. sativa. 
${ }^{b}$ Comparison among species was performed based on accessions as biological replicates except for $A$. murphyi where only one viable accession was available and multiple plants were grown instead. For A. macrostachya, only one viable plant was available and statistical inferences were not made.

${ }^{c}$ Species followed by identical lowercase letters are not significantly different at $\alpha=0.05$ based on an unadjusted Fisher's least significant difference (LSD) test.

${ }^{d}$ Species followed by identical lowercase letters are not significantly different at $\alpha=0.05$ based on an unadjusted Tukey's honest significance difference (HSD) test.

${ }^{e}$ The characters $\mathrm{V}$ and $\mathrm{P}$ represent the internal reference standard species Vicia faba and Pisum sativum, respectively.

${ }^{\mathrm{f}}$ A. insularis has occasionally been designated CD (e.g., Loskutov, 2008). Although this constitution has not been substantiated, the similarity between $\mathrm{A}$ and $\mathrm{D}$ genomes remains a potential source of revision. 
Table 2. Nested analysis of variance (ANOVA) of genome size (pg/2C) in the genus Avena..

\begin{tabular}{llllll}
\hline Source $^{a}$ & df & MS & F & Sig. & Variance $^{c}$ \\
\hline Ploidy & 2 & 5287.611 & 133.8 & $<0.0001$ & NA \\
Genome & 7 & 26.354 & 30.5 & $<0.0001$ & 2.201 \\
Species & 16 & 1.025 & 9.12 & $<0.0001$ & 0.058 \\
Accession & 85 & 0.114 & 2.70 & $(<0.0001)^{b}$ & 0.018 \\
Error & 252 & 0.042 & & & 0.047
\end{tabular}

${ }^{a}$ Ploidy is a fixed factor with three levels (diploid, tetraploid, hexaploid) and 2 degrees of freedom (df). Remaining factors are considered random (as required to estimate variance components of a nested design) with df equal to one less than the number of observed levels minus the df used in the preceding level. For example, the ten genome levels (As, Ac, Ad, Al, $\mathrm{Cp}, \mathrm{Cv}, \mathrm{AB}, \mathrm{AC}, \mathrm{CmCm}$, and ACD) within three ploidy levels leaves seven df.

${ }^{b}$ The significance test of accessions is not entirely valid because technical replicates, which form the error term, were not randomly assigned. This variance ratio and significant test are reported as guidance to the scale of variance components.

${ }^{c}$ Variance components were estimated by REML in SPSS. A parallel analysis using the package 'nlme' in $\mathrm{R}$, gave similar results. 
Table 3. Comparison of present and previous estimates of genome size in Avena species.

\begin{tabular}{|c|c|c|c|c|}
\hline \multirow{2}{*}{ Species $^{a}$} & \multirow{2}{*}{$\begin{array}{l}2 \mathrm{C} \text { value (pg) } \\
\text { Present study }\end{array}$} & \multicolumn{3}{|c|}{$2 \mathrm{C}$ value (pg) reported in previous studies } \\
\hline & & $\begin{array}{l}\text { Bullen and Rees } \\
(1972)^{b}\end{array}$ & $\begin{array}{l}\text { Iimaya and Grant } \\
(1972)^{c}\end{array}$ & $\begin{array}{l}\text { Bennet and Smith } \\
\text { (1976) }\end{array}$ \\
\hline A. brevis & 8.98 & $8.9(10.8)$ & & 9.5 \\
\hline A. strigosa & 9.07 & $9.7(11.7)$ & 10 & 8 \\
\hline A. hirtula & 9.08 & $9.4(11.4)$ & 9.8 & 8.8 \\
\hline A. nuda & 9.08 & $8.8(10.6)$ & & \\
\hline A. wiestii & 9.08 & $10.3(12.4)$ & 9.8 & \\
\hline A. longiglumis & 9.23 & $9.9(12.0)$ & 9.8 & 10.6 \\
\hline A. eriantha & 10.18 & & 11 & 9.5 \\
\hline A. ventricosa & 10.29 & & 10.9 & \\
\hline A. clauda & 10.31 & & 10.6 & \\
\hline A. vavilovana & 16.38 & $17.0(20.5)$ & 18.4 & \\
\hline A. barbata & 16.42 & $18.5(22.4)$ & 18.1 & 17.8 \\
\hline A. abyssinica & 16.73 & $17.9(21.6)$ & 18 & 9.6 \\
\hline A. maroccana & 18.51 & & 19.4 & 18.6 \\
\hline A. sativa & 25.7 & $27.5(33.2)$ & & 26.5 \\
\hline A. sterilis & 25.75 & $28.6(34.5)$ & 28.2 & 27.3 \\
\hline A. fatua & 25.81 & $28.3(34.2)$ & 25.7 & \\
\hline
\end{tabular}

${ }^{a}$ The species A.nudi-brevis, A. pilosa, and A. magna used in previous studies are synonymous to A. nuda, A. eriantha, and A. maroccana, respectively, according to Baum's (1977) monograph.

${ }^{b}$ The 2C estimates outside parentheses are absolute DNA contents re-calibrated by Bennet and Smith (1976). The values in parentheses were original data obtained from Bullen and Rees (1972).

${ }^{c}$ The $2 \mathrm{C}$ values displayed were re-calibrated by Bennet and Smith (1976). 


\section{Figure Captions}

Figure 1. Fluorescence histograms of PI-stained nuclei isolated from Avena species and internal standard plants leaves. A. Avena diploid species A. damascena ( $\mathrm{A}_{\mathrm{d}}$ genome $)$ and Vicia faba; $\mathrm{B}$. tetraploid species A. insularis (AC genome) and Vicia faba; C. hexaploid species A. sterilis (ACD genome) and Pisum sativum. Note that the absolute readings on the PI flourescene scale can vary due to several intrinsic experimental factors. For this reason C-values are computed based on the standards which are included and co-chopped with each sample assay.

Figure 2. Box plots of mean $2 \mathrm{C}$ values by accession within species. Dark horizontal lines show the median observation. Boxes above and below this line indicate quartiles. Lines at the ends of the vertical whiskers indicate extreme data points.

Figure 3. Comparison of observed (blue) and predicted (red) 2C-values in polyploid species of Avena. Predictions are based on the average A and C diploid genome sizes (8.95 and 10.26 pg, respectively), and the assumption that $\mathrm{B}$ and $\mathrm{D}$ genomes are equivalent in size to the $\mathrm{A}$ genome. Thus, predictions were: $\mathrm{AB}=2 \mathrm{~A}, \mathrm{AC}=\mathrm{A}+\mathrm{C}, \mathrm{CC}=2 \mathrm{C}$, and $\mathrm{ACD}=2 \mathrm{~A}+\mathrm{C}$. Observed values are averaged across species with a given genome constitution. 


\section{Supplemental material}

Supplemental Table S1. Genome size estimates for all accessions used in the present study including their species names, reported genome constitutions, accession numbers, origins, $2 \mathrm{C}$ value with standard deviations, average coefficient variation of $2 \mathrm{C}$ values, average number of nuclei, and average coefficient variation of the cell distributions used in genome size predictions.

Supplemental Figure S1. Box plots of residuals for individual replicates after fitting means of accessions. Dark horizontal lines show the median values. Boxes above and below this line indicate quartiles, and lines at the ends of the vertical whiskers indicate extreme data points. 

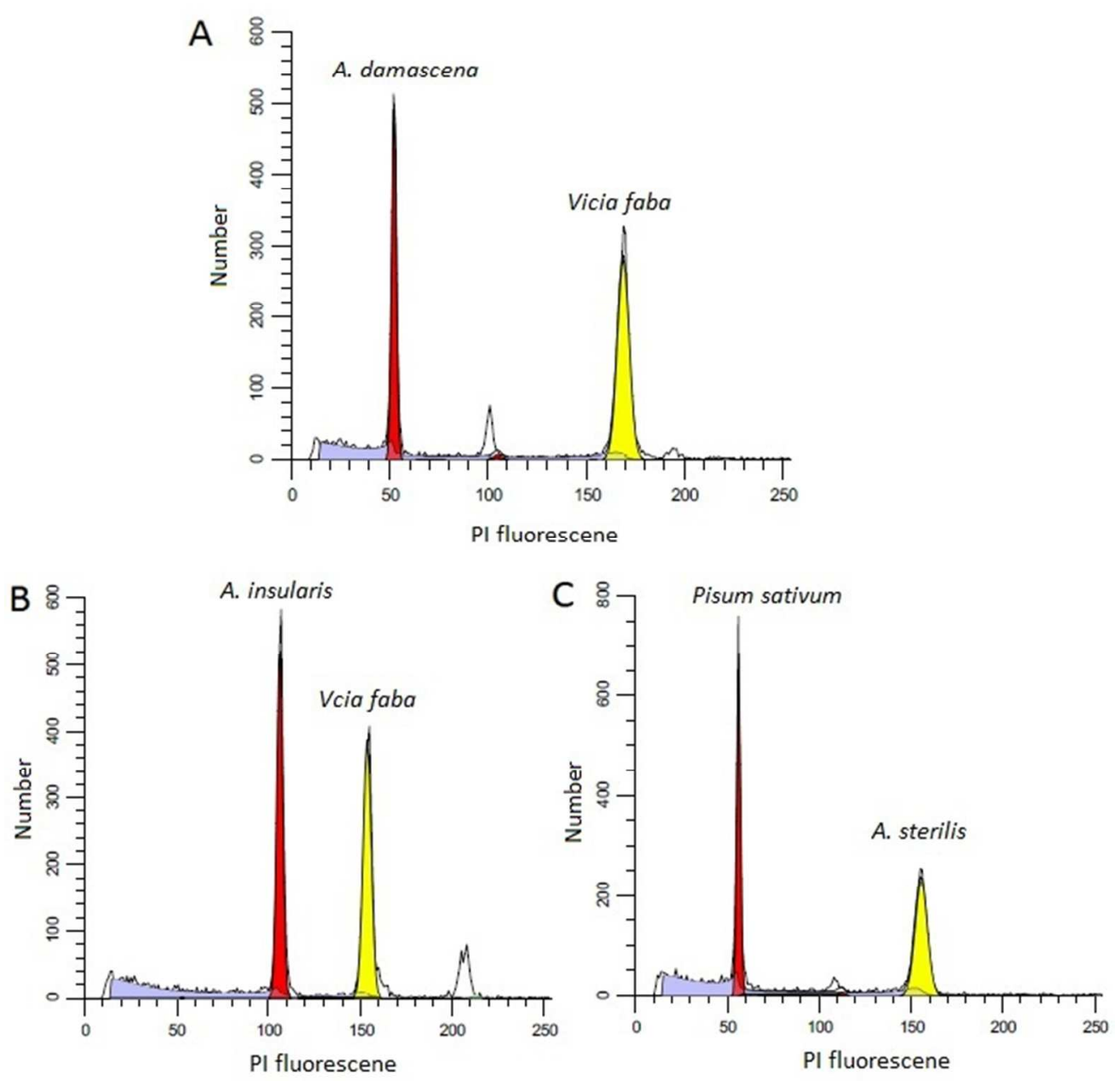

Figure 1. Fluorescence histograms of PI-stained nuclei isolated from Avena species and internal standard plants leaves. A. Avena diploid species A. damascena (Ad genome) and Vicia faba; B. tetraploid species A. insularis (AC genome) and Vicia faba; C. hexaploid species A. sterilis (ACD genome) and Pisum sativum. $183 \times 191 \mathrm{~mm}(96 \times 96 \mathrm{DPI})$ 


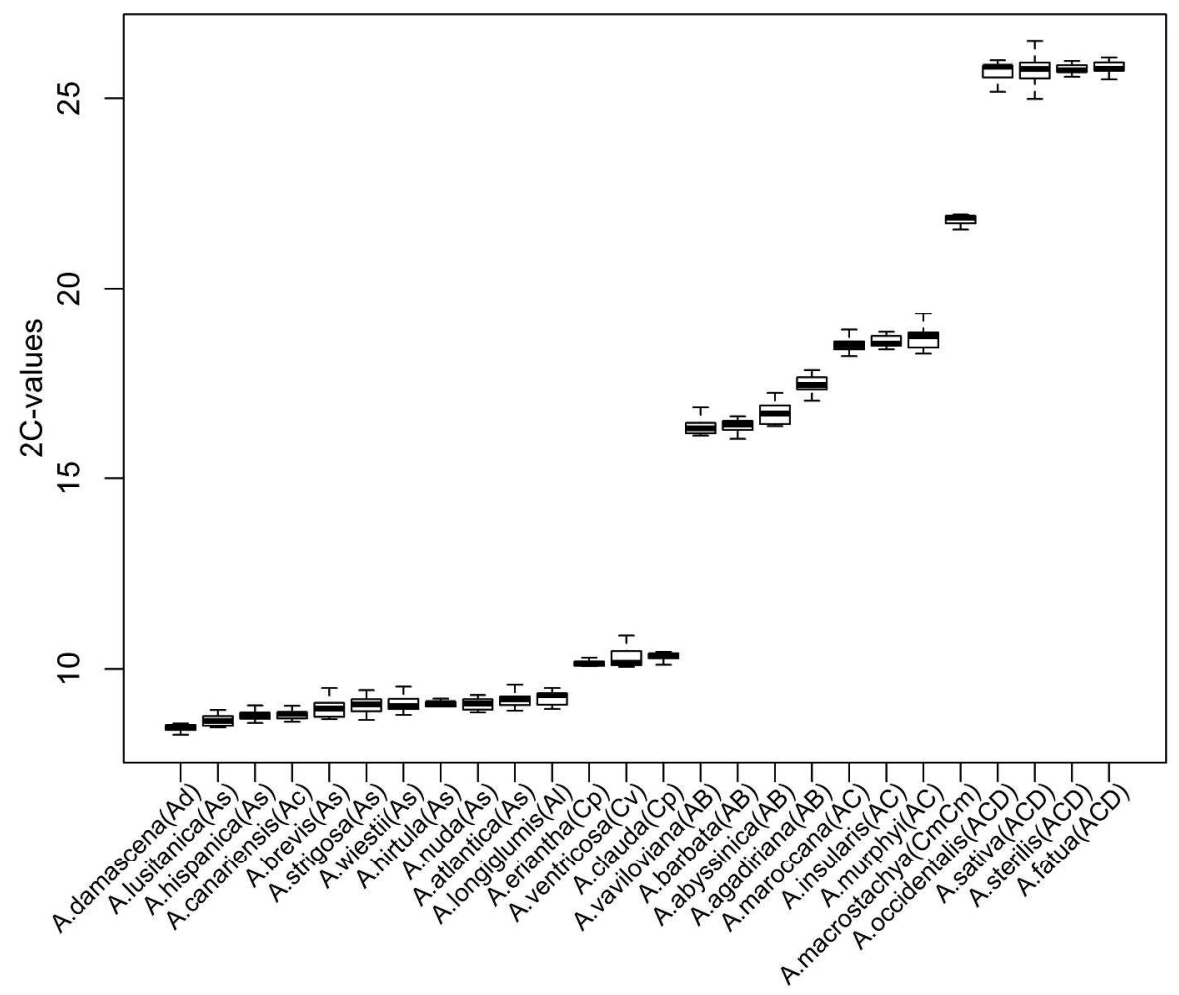

Avena species

Figure 2. Box plots of mean $2 \mathrm{C}$ values by accession within species. Dark horizontal lines show the median observation. Boxes above and below this line indicate quartiles. Lines at the ends of the vertical whiskers indicate extreme data points. $168 \times 159 \mathrm{~mm}(600 \times 600 \mathrm{DPI})$ 


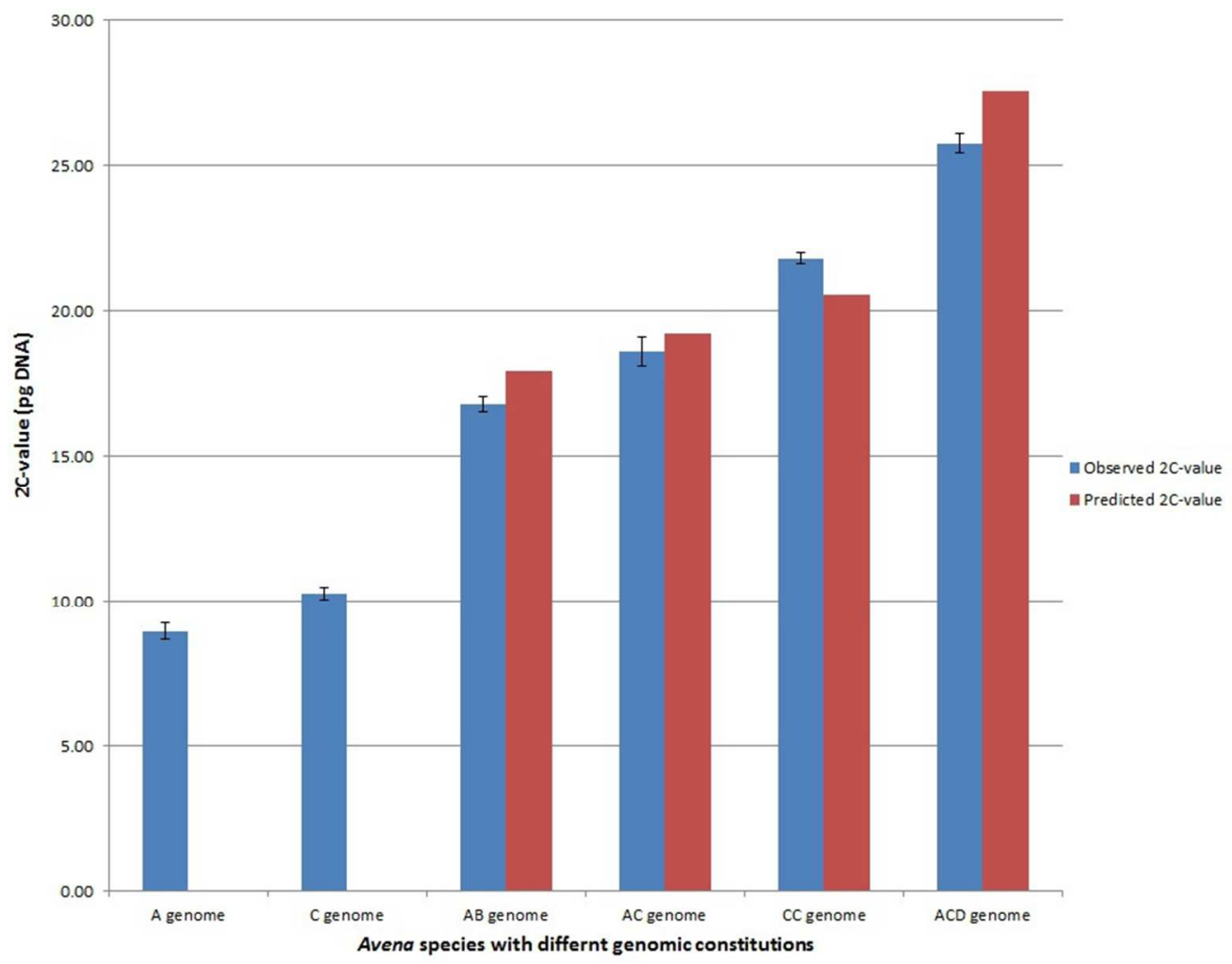

Figure 3. Comparison of observed (blue) and predicted (red) 2C-values in polyploid species of Avena. Predictions are based on the average $A$ and $C$ diploid genome sizes ( 8.95 and 10.26 pg, respectively), and the assumption that $B$ and $D$ genomes are equivalent in size to the $A$ genome. Thus, predictions were: $A B=2 A, A C=A+C, C C=2 C$, and $A C D=2 A+C$. Observed values are averaged across species with a given genome constitution. $236 \times 184 \mathrm{~mm}(96 \times 96 \mathrm{DPI})$ 
Table S1. All accessions used in the present study including their species names, reported genome constitutions, accession numbers, origins, 2C-value with standard deviations, average coefficient variation of $2 \mathrm{C}$ values, average number of nuclei, and average coefficient variation of the cell distributions used in genome size predictions.

\begin{tabular}{|c|c|c|c|c|c|c|c|}
\hline Species & Haplome & $\begin{array}{l}\text { Accession } \\
\text { No. }{ }^{a}\end{array}$ & Origin or Source & $\begin{array}{l}\text { Mean } 2 \mathrm{C} \text { values } \\
\pm \text { S.D (pg DNA) }\end{array}$ & $\mathrm{CV}_{\mathrm{t}}^{b}(\%)$ & $\begin{array}{l}\text { Mean } \\
\text { nuclei }\end{array}$ & $\begin{array}{l}\text { Mean } C V_{\mathrm{n}}{ }^{c} \\
(\%)\end{array}$ \\
\hline \multirow[t]{4}{*}{ A. atlantica } & $\mathrm{A}_{\mathrm{s}}$ & CN25849 & Morocco & $8.94 \pm 0.04$ & 0.45 & 1866 & 2.45 \\
\hline & & $\mathrm{CN} 25859$ & Morocco & $9.23 \pm 0.03$ & 0.33 & 3612 & 1.73 \\
\hline & & CN25887 & Morocco & $9.52 \pm 0.20$ & 2.10 & 2036 & 2.85 \\
\hline & & CN25897 & Morocco & $9.17 \pm 0.08$ & 0.87 & 3528 & 1.77 \\
\hline \multirow[t]{3}{*}{ A. brevis } & $A_{s}$ & CN53507 & Germany & $9.09 \pm 0.10$ & 1.10 & 2958 & 2.03 \\
\hline & & CN58163 & Ontario, Canada & $9.05 \pm 0.40$ & 4.42 & 3140 & 2.23 \\
\hline & & CN53508 & United States & $8.77 \pm 0.09$ & 1.03 & 2912 & 2.35 \\
\hline \multirow[t]{3}{*}{ A. hirtula } & $A_{s}$ & CN21703 & Morocco & $9.09 \pm 0.06$ & 0.66 & 2611 & 1.77 \\
\hline & & $\mathrm{CN} 22633$ & Tunisia & $9.01 \pm 0.16$ & 1.78 & 2737 & 1.88 \\
\hline & & CN19530 & Turkey & $9.13 \pm 0.11$ & 1.20 & 3391 & 1.80 \\
\hline \multirow[t]{3}{*}{ A. hispanica } & $\mathrm{A}_{\mathrm{s}}$ & CN25698 & Portugal & $8.96 \pm 0.10$ & 1.12 & 2056 & 1.55 \\
\hline & & $\mathrm{CN} 25727$ & Portugal & $8.71 \pm 0.04$ & 0.46 & 3513 & 2.13 \\
\hline & & $\mathrm{CN} 25787$ & Portugal & $8.74 \pm 0.12$ & 1.49 & 2617 & 2.19 \\
\hline \multirow[t]{3}{*}{ A. lusitanica } & $A_{s}$ & CN25885 & Morocco & $8.92 \pm 0.36$ & 4.04 & 2550 & 1.95 \\
\hline & & CN26265 & Portugal & $8.72 \pm 0.23$ & 2.64 & 1878 & 1.92 \\
\hline & & CN26441 & Spain & $8.52 \pm 0.11$ & 1.29 & 3473 & 1.77 \\
\hline \multirow[t]{3}{*}{ A. nuda } & $\mathrm{As}_{\mathrm{s}}$ & CN79356 & Germany & $9.06 \pm 0.17$ & 1.88 & 2222 & 1.61 \\
\hline & & CN79351 & Netherlands & $9.19 \pm 0.22$ & 2.39 & 1937 & 2.37 \\
\hline & & CN79350 & United Kingdom & $9.00 \pm 0.11$ & 1.22 & 2642 & 1.47 \\
\hline \multirow[t]{10}{*}{ A. strigosa } & $\mathrm{A}_{\mathrm{s}}$ & CN21993 & Portugal & $8.86 \pm 0.04$ & 0.56 & 6023 & 1.34 \\
\hline & & CN21994 & Portugal & $9.38 \pm 0.01$ & 0.11 & 2747 & 2.53 \\
\hline & & CN21996 & Spain & $9.18 \pm 0.20$ & 2.18 & 2704 & 2.20 \\
\hline & & CN21997 & Spain & $9.04 \pm 0.31$ & 3.54 & 1780 & 1.61 \\
\hline & & CN21998 & Spain & $8.97 \pm 0.09$ & 1.00 & 1784 & 1.77 \\
\hline & & CN21999 & Spain & $9.15 \pm 0.15$ & 1.64 & 1774 & 1.79 \\
\hline & & CN22000 & Spain & $9.11 \pm 0.22$ & 2.41 & 1798 & 1.56 \\
\hline & & CN22001 & Spain & $9.20 \pm 0.12$ & 1.30 & 2645 & 1.70 \\
\hline & & CN54038 & United Kingdom & $8.98 \pm 0.14$ & 1.67 & 2415 & 1.57 \\
\hline & & CN55100 & United Kingdom & $8.74 \pm 0.09$ & 1.14 & 2599 & 2.39 \\
\hline \multirow[t]{2}{*}{ A. wiestii } & $\mathrm{As}_{\mathrm{s}}$ & PI53626_1 & Giza, Egypt & $9.36 \pm 0.16$ & 1.71 & 1814 & 3.19 \\
\hline & & PI53626_2 & Giza, Egypt & $8.88 \pm 0.06$ & 0.79 & 2369 & 2.15 \\
\hline
\end{tabular}




\begin{tabular}{|c|c|c|c|c|c|c|c|}
\hline & & PI53626_3 & Giza, Egypt & $8.88 \pm 0.09$ & 1.01 & 2320 & 2.20 \\
\hline & & CN58104_1 & Ontario, Canada & $9.09 \pm 0.14$ & 1.54 & 2600 & 2.08 \\
\hline & & CN58104_2 & Ontario, Canada & $9.18 \pm 0.12$ & 1.31 & 3340 & 2.48 \\
\hline & & CN58104_3 & Ontario, Canada & $9.04 \pm 0.19$ & 2.10 & 2818 & 1.71 \\
\hline \multirow[t]{10}{*}{ A. canariensis } & $A_{c}$ & CN23017 & Canary Islands, & $8.87 \pm 0.15$ & 1.69 & 1700 & 2.49 \\
\hline & & & Spain & & & & \\
\hline & & CN23029 & Canary Islands, & $8.79 \pm 0.11$ & 1.37 & 1932 & 2.23 \\
\hline & & & Spain & & & & \\
\hline & & CN25442 & Canary Islands, & $8.73 \pm 0.11$ & 1.26 & 2218 & 1.89 \\
\hline & & & Spain & & & & \\
\hline & & CN26172 & Canary Islands, & $8.93 \pm 0.09$ & 1.01 & 2753 & 1.98 \\
\hline & & & Spain & & & & \\
\hline & & CN26195 & Canary Islands, & $8.70 \pm 0.06$ & 0.69 & 2204 & 1.96 \\
\hline & & & Spain & & & & \\
\hline \multirow[t]{3}{*}{ A. damascena } & $A_{d}$ & CN19457 & Syria & $8.45 \pm 0.17$ & 2.01 & 2480 & 1.83 \\
\hline & & CN19458 & Syria & $8.41 \pm 0.07$ & 0.83 & 2086 & 2.05 \\
\hline & & CN19459 & Syria & $8.44 \pm 0.10$ & 1.18 & 2290 & 1.98 \\
\hline \multirow[t]{3}{*}{ A. longiglumis } & $\mathrm{A}_{1}$ & CN58139 & Libya & $9.42 \pm 0.09$ & 0.96 & 1876 & 1.83 \\
\hline & & CN58138 & Oran, Algeria & $9.11 \pm 0.22$ & 2.41 & 1630 & 1.99 \\
\hline & & CN73757 & Setubal, Portugal & $9.17 \pm 0.13$ & 1.42 & 2366 & 2.25 \\
\hline \multirow[t]{3}{*}{ A. clauda } & $\mathrm{C}_{\mathrm{p}}$ & CN21388 & Algeria & $10.26 \pm 0.13$ & 1.27 & 3163 & 1.46 \\
\hline & & CN21378 & Greece & $10.41 \pm 0.05$ & 0.48 & 3814 & 1.88 \\
\hline & & CN19205 & Iran & $10.27 \pm 0.14$ & 1.36 & 1962 & 2.28 \\
\hline \multirow[t]{3}{*}{ A. eriantha } & $\mathrm{C}_{\mathrm{p}}$ & CN21992 & Cyprus & $10.33 \pm 0.31$ & 3.00 & 2016 & 2.65 \\
\hline & & CN58101 & United Kingdom & $10.02 \pm 0.10$ & 1.10 & 3559 & 2.00 \\
\hline & & CN73755 & Madrid, Spain & $10.19 \pm 0.10$ & 0.98 & 2820 & 1.99 \\
\hline \multirow[t]{7}{*}{ A. ventricosa } & $\mathrm{C}_{\mathrm{v}}$ & CN21405_1 & Algeria & $10.30 \pm 0.24$ & 2.33 & 2682 & 2.47 \\
\hline & & CN21405_2 & Algeria & $10.62 \pm 0.27$ & 2.54 & 1950 & 2.53 \\
\hline & & CN21405_3 & Algeria & $10.37 \pm 0.22$ & 2.12 & 2764 & 2.33 \\
\hline & & CN21405_4 & Algeria & $10.11 \pm 0.03$ & 0.30 & 1671 & 1.76 \\
\hline & & CN39706_1 & Azerbaijan & $10.10 \pm 0.05$ & 0.50 & 2022 & 2.54 \\
\hline & & CN39706_2 & Azerbaijan & $10.32 \pm 0.36$ & 3.59 & 1756 & 2.36 \\
\hline & & CN39706_3 & Azerbaijan & $10.17 \pm 0.09$ & 0.89 & 2359 & 1.46 \\
\hline \multirow[t]{4}{*}{ A. abyssinica } & $\mathrm{AB}$ & CN21939 & Ethiopia & $16.97 \pm 0.25$ & 1.47 & 1945 & 2.32 \\
\hline & & CN21941 & Ethiopia & $16.62 \pm 0.19$ & 1.14 & 1637 & 2.34 \\
\hline & & CN22076 & Ethiopia & $16.85 \pm 0.35$ & 2.08 & 1822 & 1.89 \\
\hline & & CN22092 & Ethiopia & $16.49 \pm 0.12$ & 0.73 & 2514 & 2.08 \\
\hline \multirow[t]{4}{*}{ A. agadiriana } & $\mathrm{AB}$ & CN25837 & Morocco & $17.23 \pm 0.13$ & 0.75 & 3258 & 2.55 \\
\hline & & CN25854 & Morocco & $17.68 \pm 0.21$ & 1.19 & 2576 & 2.98 \\
\hline & & CN25856 & Morocco & $17.47 \pm 0.19$ & 1.09 & 2138 & 2.59 \\
\hline & & CN25863 & Morocco & $17.59 \pm 0.09$ & 0.51 & 1960 & 2.85 \\
\hline
\end{tabular}




\begin{tabular}{|c|c|c|c|c|c|c|c|}
\hline \multirow[t]{5}{*}{ A. barbata } & $\mathrm{AB}$ & CN73713 & Beja, Portugal & $16.38 \pm 0.16$ & 0.98 & 2002 & 2.54 \\
\hline & & CN71818 & Greece & $16.39 \pm 0.12$ & 0.73 & 2121 & 2.63 \\
\hline & & CN64812 & Israel & $16.58 \pm 0.07$ & 0.42 & 2494 & 2.50 \\
\hline & & CN71804 & Izmir, Turkey & $16.32 \pm 0.19$ & 1.16 & 2969 & 2.40 \\
\hline & & PI296229 & Northern, Israel & $16.42 \pm 0.11$ & 0.61 & 2730 & 2.78 \\
\hline \multirow[t]{5}{*}{ A. vaviloviana } & $\mathrm{AB}$ & CN21905 & Ethiopia & $16.62 \pm 0.24$ & 1.44 & 1582 & 1.67 \\
\hline & & CN22004 & Ethiopia & $16.31 \pm 0.11$ & 0.74 & 2249 & 2.30 \\
\hline & & CN22005 & Ethiopia & $16.31 \pm 0.14$ & 0.92 & 2242 & 2.25 \\
\hline & & CN22228 & Ethiopia & $16.35 \pm 0.15$ & 0.92 & 2168 & 2.18 \\
\hline & & CN22422 & Ethiopia & $16.33 \pm 0.16$ & 0.98 & 2354 & 2.26 \\
\hline \multirow[t]{3}{*}{ A. insularis } & $\mathrm{AC}$ & CN19178 & Italy & $18.43 \pm 0.05$ & 0.27 & 1577 & 1.54 \\
\hline & & CN108634 & Tunisia & $18.79 \pm 0.06$ & 0.32 & 2814 & 2.29 \\
\hline & & CN108635 & Tunisia & $18.54 \pm 0.04$ & 0.22 & 2358 & 2.28 \\
\hline \multirow[t]{3}{*}{ A. maroccana } & $\mathrm{AC}$ & Cia8831 & Khemisset, Morocco & $18.31 \pm 0.09$ & 0.49 & 2286 & 2.82 \\
\hline & & CN23044 & Morocco & $18.56 \pm 0.09$ & 0.48 & 2012 & 1.94 \\
\hline & & CN23049 & Morocco & $18.67 \pm 0.21$ & 1.12 & 2854 & 2.47 \\
\hline \multirow[t]{4}{*}{ A. murphyi } & $\mathrm{AC}$ & CN21989_1 & Spain & $18.58 \pm 0.15$ & 0.81 & 2342 & 2.31 \\
\hline & & CN21989_2 & Spain & $18.56 \pm 0.28$ & 1.51 & 2610 & 2.54 \\
\hline & & CN21989_3 & Spain & $18.59 \pm 0.25$ & 1.34 & 2582 & 2.35 \\
\hline & & CN21989_4 & Spain & $19.13 \pm 0.29$ & 1.57 & 1798 & 2.34 \\
\hline A. macrostachya & $\mathrm{C}_{\mathrm{m}} \mathrm{C}_{\mathrm{m}}$ & CN24393 & Algeria & $21.78 \pm 0.20$ & 0.96 & 1993 & 2.23 \\
\hline \multirow[t]{3}{*}{ A. fatua } & $\mathrm{ACD}$ & CN24919 & Iran & $25.90 \pm 0.16$ & 0.62 & 1593 & 2.05 \\
\hline & & CN24167 & Israel & $25.76 \pm 0.29$ & 1.13 & 2467 & 1.84 \\
\hline & & CN22544 & Turkey & $25.77 \pm 0.05$ & 0.19 & 2752 & 2.01 \\
\hline \multirow[t]{3}{*}{ A. occidentalis } & $\mathrm{ACD}$ & $\mathrm{CN} 23036$ & Spain & $25.44 \pm 0.37$ & 1.45 & 2502 & 2.03 \\
\hline & & CN4541 & Spain & $25.81 \pm 0.18$ & 0.70 & 1210 & 1.73 \\
\hline & & CN4547 & Spain & $25.77 \pm 0.19$ & 0.74 & 1822 & 2.44 \\
\hline \multirow[t]{13}{*}{ A. sativa } & $\mathrm{ACD}$ & CN2807 & United States & $25.50 \pm 0.31$ & 1.26 & 1450 & 1.68 \\
\hline & & CN28697 & United States & $25.85 \pm 0.09$ & 0.35 & 1623 & 1.64 \\
\hline & & CN18136 & Canada & $25.90 \pm 0.05$ & 0.19 & 2189 & 2.05 \\
\hline & & CN4703 & Canada & $25.87 \pm 0.48$ & 1.86 & 3182 & 2.31 \\
\hline & & CN22330 & Ethiopia & $26.24 \pm 0.22$ & 0.84 & 1516 & 1.92 \\
\hline & & CN65923 & Romania & $25.56 \pm 0.60$ & 2.35 & 3331 & 2.49 \\
\hline & & CN1954 & South Africa & $25.43 \pm 0.31$ & 1.22 & 2402 & 2.44 \\
\hline & & CN25416 & Spain & $25.84 \pm 0.22$ & 0.85 & 1319 & 1.60 \\
\hline & & CN53087 & Sweden & $25.97 \pm 0.22$ & 0.85 & 2349 & 2.15 \\
\hline & & CN53094 & Sweden & $25.49 \pm 0.67$ & 2.67 & 2079 & 2.46 \\
\hline & & CN53165 & Sweden & $25.74 \pm 0.16$ & 0.62 & 2030 & 2.39 \\
\hline & & CN53326 & Sweden & $25.30 \pm 0.09$ & 0.36 & 2176 & 2.58 \\
\hline & & CN53173 & United States & $25.46 \pm 0.31$ & 1.22 & 1906 & 2.30 \\
\hline A. sterilis & $\mathrm{ACD}$ & CN20234 & Iraq & $25.94 \pm 0.25$ & 0.96 & 1424 & 1.77 \\
\hline
\end{tabular}




$\begin{array}{llllll}\text { CN20239 } & \text { Iraq } & 25.78 \pm 0.07 & 0.27 & 1235 & 1.80 \\ \text { CN19991 } & \text { Mazandaran, Iran } & 25.79 \pm 0.16 & 0.62 & 1415 & 1.57 \\ \text { CN20982 } & \text { Turkey } & 25.49 \pm 0.26 & 1.02 & 2406 & 1.72\end{array}$

${ }^{a}$ The underscore and number after the same accession number represent different plants of this accession.

${ }^{b}$ The $\mathrm{CV}_{\mathrm{t}}$ represents the coefficient of variation among $2 \mathrm{C}$ values of technical replications on separate days.

${ }^{c}$ The $\mathrm{CV}_{\mathrm{n}}$ represents the coefficient of variation for the distribution of nucluei, averaged over technical replications. 


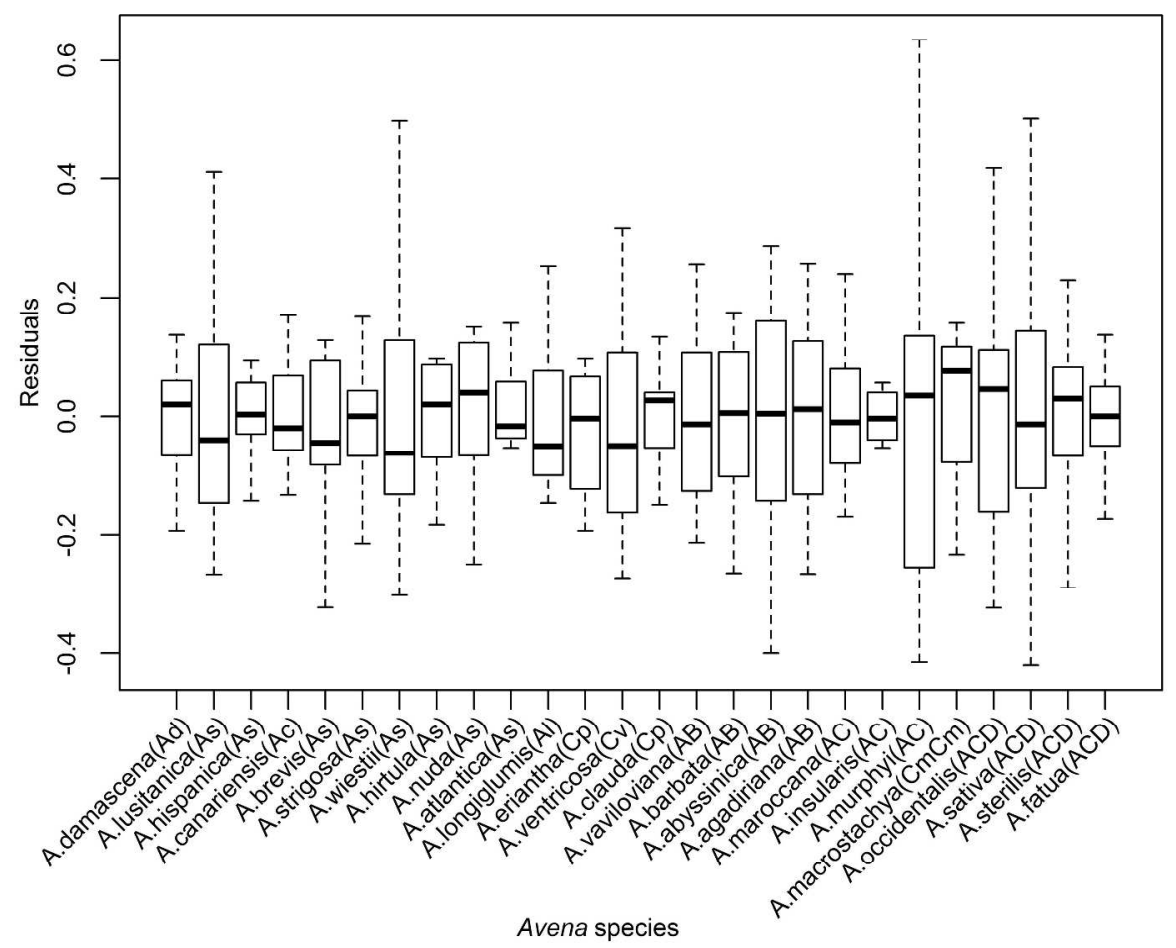

$168 \times 159 \mathrm{~mm}(600 \times 600 \mathrm{DPI})$ 